\title{
Reprodução de Meloidogyne exigua em Cultivares de Cafeeiros Resistentes e Suscetíveis
}

\author{
Sônia M. Lima Salgado, Mário Lúcio V. Resende \& Vicente P. Campos \\ Departamento de Fitopatologia, Universidade Federal de Lavras, Campus Universitário, Cx. Postal 3037, \\ CEP 37200-000, Lavras, MG, Fax (035) 3829-1283, e-mail: solisa@ufla.br
}

(Aceito para publicação em 12/01/2005)

Autor para correspondência: Sônia M. Lima Salgado

SALGADO, S.M.L., RESENDE, M.L.V. \& CAMPOS, V.P. Reprodução de Meloidogyne exigua em cultivares de cafeeiros resistentes e suscetíveis. Fitopatologia Brasileira 30:413-415. 2005.

\section{RESUMO}

A resistência do cafeeiro (Coffea arabica) Iapar-59 a Meloidogyne exigua foi comparada com a cultivar IACApoatã, empregada como padrão de resistência, e com as cultivares suscetíveis Mundo Novo (IAC 379-19), Catuaí (IAC 62) e Tupi (IAC 1669-33). Plantas de um ano de idade foram inoculadas com 10.000 ovos de M. exigua. Aos 93 dias da inoculação avaliou-se a reprodução de $M$. exigua através do número de galhas (NG), número de ovos (NO), fator de reprodução (FR), reducão no fator de reprodução e comportamento dos cafeeiros. Menor reprodução de $M$. exigua foi igualmente $(\mathrm{P} \leq 0,05)$ observada nos cafeeiros Iapar-59 e Apoatã, nos quais o IG, NO e FR foram menores do que aqueles observados nas cultivares Mundo Novo, Catuaí e Tupi. Maior redução no FR de M. exigua ocorreu nos cafeeiros Apoatã e Iapar-59, indicando a reação de resistência do Iapar-59.

Palavras-chave adicionais: nematóide das galhas, resistência, Coffea arabica, C. canephora.

\begin{abstract}
Reproduction of Meloidogyne exigua on resistant and susceptible coffee cultivars

The resistance of the Iapar-59 coffee (Coffea arabica) cultivar to Meloidogyne exigua was compared with cv. IAC-Apoatã, used as a resistance standard, and with susceptible cultivars Mundo Novo (IAC 379-19), Catuaí (IAC 62) and Tupi (IAC 1669-33). One-year old plants were inoculated with 10,000 of M. exigua eggs and 93 days after inoculation, the reproduction of $M$. exigua was evaluated by determining the number of galls (NG), the number of eggs (NO), the reproduction factor $(\mathrm{RF})$, reduction in the reproduction factor (RFR) and behaviour of the coffee plant. A lower degree of $M$. exigua reproduction was equally observed in 'Iapar-59' and 'Apoatã', in which NG, NO and the FR were lower then those observed in 'Mundo Novo', 'Catuaí' and 'Tupi'. Greater reduction in the reproduction factor (RFR) of M. exigua observed in 'Apoatã' and 'Iapar-59' indicaties a resistance reaction of 'Iapar-59'.
\end{abstract}

Additional keywords: root knot nematodes, resistance, Coffea arabica, C. canephora.

Meloidogyne exigua Goeldi, 1887, está amplamente disseminado nas lavouras cafeeiras (Coffea arabica L.), podendo causar declínio na produção, notadamente, quando os cafezais são implantados e conduzidos em solo arenoso ou argilo-arenoso. Esse decréscimo de produção deve-se, em parte, por tratar-se de uma cultura perene, na qual os cafeeiros propiciam condições para o aumento dos nematóides durante quase o ano todo, podendo esse parasita alcançar altos níveis populacionais, em todas as fases fenológicas do cafeeiro (Zambolim \& Vale, 2003).

A resistência de plantas tem sido considerada como uma das principais táticas de manejo de fitonematóides, principalmente, para os endoparasitos sedentários, como os do gênero Meloidogyne, que apresentam uma interação especializada com seus hospedeiros (Roberts, 2002).

Um dos critérios para avaliar a resistência a fitonematóides é dimensionar as taxas reprodutivas dos mesmos em seus hospedeiros. Trabalhos de pesquisa demonstraram que a resistência à $M$. exigua é de ocorrência comum em introduções de várias espécies de Coffea, inclusive
C. arabica (oriundas da Etiópia, germoplasma de Icatu, Catimor e híbrido de Timor). Dentre os materiais resistentes a nematóides a cultivar Apoatã (IAC 2258), material pertencente à espécie Coffea canephora Pierre, é recomendada para plantio em áreas infestadas com nematóides $M$. exigua, $M$. incognita (Kofoid \& White) Chitwood e $M$. paranaensis Carneiro et al. Com vistas à seleção para resistência à ferrugem, a cultivar Iapar-59 (seleção 75163-22 de LC-1669), obtida pelo Instituto Agronômico do Paraná, resultou de um intenso trabalho de seleção no germoplasma Sarchimor (resultante do cruzamento Villa sarchi 971/10 x híbrido de Timor 832/2) (Mendes et al., 2002).

O estudo da reação de cafeeiros IAPAR-59 a $M$. exigua, incluindo padrões suscetíveis e resistentes não tem sido relatado. Diante disso, objetivou-se avaliar a reprodução de M. exigua em cafeeiros Iapar-59, Apoatã, Mundo Novo, Catuaí e Tupi.

O inóculo de $M$. exigua foi obtido pela extração de ovos de raízes de cafeeiros com galhas, empregando-se a 
técnica de Hussey \& Barker (1973).

Mudas de cafeeiros Iapar-59, Catuaí (IAC 62), Mundo Novo (IAC 379-19), Tupi (IAC 1669-33) de $C$. arabica e de IAC-Apoatã de C. canephora, foram transplantadas para vasos plásticos (capacidade 3 litros) contendo solo argiloso e areia (1:1). As plantas foram mantidas em casa de vegetação e com um ano de idade foram inoculadas com 10.000 ovos de M. exigua, distribuídos em orifícios ao redor da planta.

O experimento obedeceu ao modelo de blocos casualizados com quatro repetições, sendo a parcela representada pela média de cinco unidades amostrais. A reprodução de $M$. exigua foi avaliada pelo número de galhas por sistema radicular (NG), número de ovos (NO)/grama de raízes e estimou-se o valor do fator de reprodução (FR= População final/População inicial). Os dados foram transformados para $\sqrt{\mathrm{x}+0.5}$ e submetidos à análise de variância e teste de médias de acordo com Scott \& Knott (1974).

Menor reprodução de $M$. exigua ocorreu $(\mathrm{P} \leq 0,05)$ nos cafeeiros Apoatã e Iapar-59, conforme observado pela taxa reprodutiva do nematóide. Por outro lado, a reprodução do parasito foi maior $(\mathrm{P} \leq 0,05)$ nas plantas de Catuaí, Mundo Novo e Tupi (Tabela 1).

O NO observado na cultivar Mundo Novo (Tabela 1), é menor que o NO obtido por Silvarolla et al. (1998). Já em plantas de Catuaí e Mundo Novo, o FR e o NO são menores que aqueles obtidos por Gonçalves \& Pereira (1998), nessas cultivares. Talvez essa menor reprodução de $M$. exigua comparado com esses trabalhos se deva ao período de inverno prolongado durante a realização do presente trabalho, onde os cafeeiros foram mantidos em casa de vegetação sem controle de temperatura. Diante disso foram utilizados os critérios de Moura (1997) para classificação de hospedeiros, baseados na redução do fator de reprodução (RFR) que por

TABELA 1 - Reprodução de Meloidogyne exigua em cafeeiros (Coffea arabica) inoculados com 10.000 ovos e avaliados aos 93 dias após a inoculação

\begin{tabular}{lrrccc}
\hline \hline Cafceiro & $\begin{array}{c}\mathbf{N O}^{1} / \mathbf{g} \text { de } \\
\text { raiz }\end{array}$ & \multicolumn{1}{c}{ NG $^{2}$} & FR & RFR $^{3}$ & $\mathbf{C}^{\mathbf{d}}$ \\
\hline Iapar-59 & $14,256 \mathbf{a}^{5}$ & $10,582 \mathrm{a}$ & $\mathbf{0 , 0 6 1} \mathbf{a}$ & $\mathbf{9 3 , 8}$ & $\mathbf{R}$ \\
Apoatã & $\mathbf{9 , 6 1 5} \mathbf{a}$ & $\mathbf{0 , 7 4 9} \mathbf{a}$ & $\mathbf{0 , 0 0 8} \mathbf{a}$ & $\mathbf{9 9 , 2}$ & $\mathbf{A R}$ \\
Catuaí & $545,632 \mathrm{~b}$ & $215,499 \mathrm{~b}$ & $\mathbf{0 , 9 7 9} \mathrm{b}$ & $\mathbf{P a d r a ̃ o}$ & $\mathbf{S}$ \\
Mundo Novo & $170,948 \mathrm{~b}$ & $169,499 \mathrm{~b}$ & $\mathbf{0 , 8 4 5} \mathrm{b}$ & $\mathbf{1 3 , 7}$ & $\mathbf{S}$ \\
Tupi & $216,210 \mathrm{~b}$ & $188,582 \mathrm{~b}$ & $\mathbf{0 , 6 4 2} \mathrm{b}$ & $\mathbf{3 4 , 4}$ & $\mathbf{S}$ \\
\hline
\end{tabular}

${ }^{1} \mathrm{NO}$ - número de ovos; ${ }^{2} \mathrm{NG}$ - número de galhas;

${ }^{5}$ Médias seguidas pela mesma letra na coluna são iguais estatisticamente pelo teste Scott-Knott $(\mathrm{P} \leq 0,05)$. NO:número de ovos; NG:número de galhas por sistema radicular e FR (Fator de reprodução)=População final /População inicial.

${ }^{4}$ Redução do fator de reprodução $($ RFR $)=\underline{\text { Frp - Frt }} \times 100 ;$ Frp

onde: Frp = redução no fator de reprodução no padrão;

Frt $=$ fator de reprodução no tratamento.

${ }^{5}$ Comportamento dos cafeeiros: AR =Altamente Resistente $(95,0-99,9) ; \mathrm{R}=$ Resistente $(90,0-94,9) ; \mathrm{MR}=$ Moderadamente Resistente $(75,0-89,9)$; e $S=$ Suscetível (menor que 75,0), adaptado de Moura (1997). sua vez expressam melhor os resultados (Tabela 1).

O número de ovos, de galhas e o fator de reprodução de M. exigua no cafeeiro Iapar-59 são estatisticamente iguais aos do Apoatã (Tabela 1). De acordo com Mendes et al. (2002), Apoatã é um material pertencente à espécie $C$. canephora e Iapar-59 resulta de intenso melhoramento no cruzamento Villa sarchi 971/10 x híbrido de Timor 832/2. O progenitor híbrido de Timor resulta do cruzamento de $C$. arabica $\mathrm{x} C$. canephora.

A resistência do cultivar Iapar-59 a $M$. exigua foi verificada também por Bertrand et al. $(1998,1999)$ e Salgado et al. (2002). Essa resistência possivelmente ocorreu após a penetração do nematóide, confirmando os resultados de Salgado et al. (2003), cujos autores observaram também a penetração de $M$. exigua nas raízes de Iapar-59 e Apoatã, porém com reduzido número de galhas e ovos comparado com as cultivares suscetíveis.

A resistência do Iapar-59 a $M$. exigua provavelmente vem do híbrido de Timor, pois segundo Mendes et al. (2002), a resistência a nematóides proveniente desse material temse mostrado dominante e monogênica. $\mathrm{O}$ presente trabalho indica que essa resistência é do tipo pós-infeccional devido à presença de ovos e galhas nas raízes (Tabela 1). Roberts (2002) esclarece que a resistência de plantas ao nematóide das galhas, em geral, não protege a planta contra a penetração de juvenis, mas afeta o desenvolvimento ou a reprodução do nematóide. Por isso, acredita-se que a presença de $M$. exigua nas raízes de plantas resistentes como Iapar-59 e Apoatã seja responsável por desencadear o processo de defesa do cafeeiro através da interação entre substâncias produzidas pelo nematóide e pela célula vegetal desde o início da penetração ocorrendo, por conseguinte, a indução da expressão de genes de defesa da planta. De fato, em algodoeiro resistente a $M$. incognita ocorreu expressão de genes de defesa após a penetração na raiz, sendo essa expressão induzida pelo nematóide e temporariamente correlacionada com a resposta de resistência da planta (Callahan et al., 1997).

A caracterização bioquímica da resposta de defesa de cafeeiros resistentes como o Iapar-59 e Apoatã, após a penetração dos juvenis possibilitará um maior entendimento dos fatores envolvidos nessa reação de defesa da planta e de sua provável similaridade com a resistência à nematóides apresentada por outras plantas.

\section{AGRADECIMENTOS}

À Fundação de Amparo a Pesquisa de Minas Gerais pela concessão de bolsa de recém-doutor à Sonia M. Lima Salgado.

\section{REFERÊNCIAS BIBLIOGRÁFICAS}

BERTRAND, B., CILAS, C., HERVÉ, G., ANTHONY, F., ETIENNE, H. \& VILLAIN, L. Relations entre les populacions de nematodes Meloidogyne exigua et. Pratylenchus sp. dans les vaicenes de Coffea arabica na Costa Rica. Plantations: Recherche 
Developpement 5:281-286. 1998.

BERTRAND, B., ETIENNE, H., SANTACREO, R., ANZUETO, F. \& ANTHONY, F. El mejoramiento genético en América Central. Anais, III Seminário Internacional sobre Biotecnologia na Agroindústria Cafeeira. Londrina, PR, 1999. pp.231-243.

CALLAHAN, F.E., JENKINS, J.N., CREECH, R.G. \& LAWRENCE, G.W. Changes in cotton root proteins correlated with resistance to root knot nematode development. Journal of Cotton Science 1:38-47. 1997.

CAMPOS, V.P. Café (Coffea arabica L.) Controle de doenças. Doenças causadas por nematóides. In: Vale, F.X.R. \& Zambolim, L. (Eds.) Controle de doenças de plantas. Viçosa, MG:UFV. 1997. pp.141-180.

GONÇALVES, W. \& PEREIRA, A. A. Resistência do cafeeiro a nematóides. IV- Reação de cafeeiros derivados do Híbrido de Timor a Meloidogyne exigua. Nematologia Brasileira 22:39-50. 1998.

MENDES, A.N.G., GUIMARÃES, R.J. \& SOUZA, C.A.S. Classificação botânica, origem e distribuição geográfica do cafeeiro. In: Guimarães, R.J., Mendes, A.N.G. \& Souza, C.A.S. (Eds.) Cafeicultura. Lavras, MG: UFLA/FAEPE. 2002. pp.39-99.

HUSSEY, R.S. \& BARKER, R.K. A comparison of methods of collecting inocula of Meloidogyne spp., including a new technique. Plant Disease Reporter 57:1025-1028. 1973.

MOURA, R. M. O gênero Meloidogyne e a meloidoginose - Parte II. Revisão Anual de Patologia de Plantas 5:281-315. 1997.

ROBERTS, P. A. Concepts and consequences of resistance. In: Starr, J.L., Cook, R. \& Bridge, J. (Eds.). Plant Resistance to Parasitic
Nematodes. CAB International. pp.23-41. 2002.

SALGADO, S.M.L., CAMPOS, H.D., PAIVA, B.R.T.L., RESENDE, M.L.V. \& CAMPOS, V.P. Penetração de Meloidogyne exigua em cultivares de cafeeiro. Fitopatologia Brasileira 28:293. 2003. (Resumo).

SALGADO, S.M.L., CAMPOS, V.P., KRZYZANOWSKI, A.A. \& RESENDE, M.L.V. Resistência de cafeeiros a Meloidogyne exigua Goeldi, 1887. Simpósio De Pesquisa dos Cafés do Brasil, II, Vitória, Resumos, 2001. p.96.

SALGADO, S.M.L., CAMPOS, V.P., RESENDE, M.L.V. \& KRZYZANOWSKI, A.A. Reprodução de Meloidogyne exigua em cafeeiros Iapar-59 e Catuaí. Nematologia Brasileira 26:205-207. 2002.

SCOTT, A.J. \& KNOTT, M. Cluster analysis method for grouping means in the analysis of variance. Biometrics 30:507-512. 1974.

SILVAROLlA, M. B., GONÇALVES, W. \& LIMA, M. M. A. Resistência do cafeeiro a nematóides V - Reprodução de Meloidogyne exigua em cafeeiros derivados da hibridação de Coffea arabica com C. canephora. Nematologia Brasileira 22:5159. 1998.

SOUZA, J.T., MAXIMINIANO, C. \& CAMPOS, V. P. Nematóides parasitos encontrados em cafeeiros em campo e em viveiros de mudas do Estado de Minas Gerais. Summa Phytopathologica 25:180-183. 1999.

ZAMBOLIM, L. \& VALE, F.X.R. do. Estratégias múltiplas no manejo integrado de doenças do cafeeiro. Fitopatologia Brasileira 28:137-153. 2003. (Resumo) 